Published in final edited form as:

Nat Rev Microbiol. 2009 October ; 7(10): . doi:10.1038/nrmicro2218.

\title{
The structural biology of type IV secretion systems
}

\author{
Rémi Fronzes ${ }^{*}$, Peter J. Christie ${ }^{\ddagger}$, and Gabriel Waksman* \\ *Institute of Structural and Molecular Biology, Malet Street, London WC1E 7HX, UK \\ FUniversity of Texas, Houston Medical School, Department of Microbiology and Molecular \\ Genetics, 6431 Fannin Street, Houston, Texas 77030, USA
}

\begin{abstract}
Type IV secretion systems (T4SSs) are versatile secretion systems that are found in both Gramnegative and Gram-positive bacteria and secrete a wide range of substrates, from single proteins to protein-protein and protein-DNA complexes. They usually consist of 12 components that are organized into ATP-powered, double-membrane-spanning complexes. The structures of single soluble components or domains have been solved, but an understanding of how these structures come together has only recently begun to emerge. This Review focuses on the structural advances that have been made over the past 10 years and how the corresponding structural insights have helped to elucidate many of the details of the mechanism of type IV secretion.
\end{abstract}

In all living organisms, secretion systems mediate the passage of macromolecules across cellular membranes. In bacteria, secretion is essential for virulence and survival. Gramnegative bacteria use specialized envelope- spanning multiprotein complexes to secrete macromolecules (BOX 1). Among these secretion systems, type IV secretion systems (T4SSs) are exceptionally versatile: unlike most secretion systems, T4SSs are found in both Gram-negative and Gram-positive bacteria and, at least in Gram-negative bacteria, they mediate the secretion of monomeric proteins, multisubunit protein toxins and nucleoprotein complexes.

\section{Box 1}

Schematic overview of the major protein secretion systems in Gramnegative bacteria

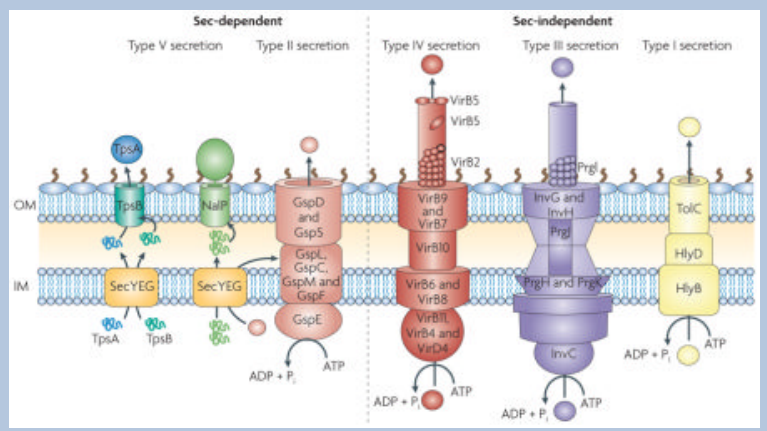

Type I secretion

(C) 2009 Macmillan Publishers Limited. All rights reserved

Correspondence to: G.W. and P.J.C, g.waksman@ucl.ac.uk; Peter.J.Christie@uth.tmc.edu. 
Type I secretion systems (T1SSs), exemplified by the haemolysin secretion system in Escherichia coli (see the figure), are simple, tripartite systems facilitating the passage of proteins of various sizes across the cell envelope of Gram-negative bacteria. They consist of an ATP-binding cassette (ABC) transporter or a proton-antiporter, an adaptor protein that bridges the inner membrane (IM) and outer membrane (OM), and an outer membrane pore. They secrete substrates in a single step without a stable periplasmic intermediate $^{115}$. T1SSs are involved in the secretion of cytotoxins belonging to the RTX (repeats-in-toxin) protein family, cell surface layer proteins, proteases, lipases, bacteriocins and haem-acquisition proteins (reviewed in REF. 116).

\section{Type II secretion}

Type II secretion systems (T2SSs) are multicomponent machines that use a two-step mechanism for translocation. During the first step, the precursor effector protein is translocated through the inner membrane by the Sec translocon ${ }^{117}$ or the Tat pathway ${ }^{118}$. Once in the periplasm, the effector protein is translocated by the T2SS through the outer membrane. The T2SS translocon consists of $12-16$ protein components ${ }^{114}$ that are found in both bacterial membranes, the cytoplasm and the periplasm. As an example, the general secretion pathway (Gsp) system is shown (see the figure). The T2SS shows an evolutionary relationship with the type IV pilus assembly machinery ${ }^{119,120}$.

\section{Type III secretion}

Type III secretion systems (T3SSs), also called injectisomes, mediate a single-step secretion mechanism and are used by many plant and animal pathogens, including Salmonella spp., Shigella spp., Yersinia spp., enteropathogenic and enterohaemorrhagic Escherichia coli and Pseudomonas aeruginosa. The T3SS is illustrated by the Salmonella enterica subsp. enterica serovar Typhimurium system, which uses the invasion (Inv) and Prg proteins (see the figure). T3SSs deliver effector proteins into the eukaryotic host cell cytoplasm in a Sec-independent manner ${ }^{121}$. T3SSs are genetically, structurally and functionally related to bacterial flagella ${ }^{121}$. They are composed of more than 20 different proteins, which form a large supramolecular structure crossing the bacterial cell envelope ${ }^{121,122}$.

\section{Type IV secretion}

Type IV secretion systems are versatile systems that are found in Gram-negative and Gram-positive bacteria and that secrete a wide range of substrates, from single proteins to protein-protein and protein-DNA complexes. These systems are exemplified by the Agrobacterium tumefaciens VirB/D system (see the figure). See main text for further details.

\section{Type V secretion}

Type V secretion systems (T5SSs) include autotransporters and two-partner secretion systems. T5SSs translocate substrates in two steps ${ }^{123}$. Autotransporter proteins, such as NalP from Neisseria meningitidis (see the figure), are multidomain proteins that are secreted as precursor proteins across the inner membrane in a Sec-dependent process. Subsequently, the translocator domain of the protein inserts into the outer membrane and facilitates surface localization of the passenger domain. In two-partner secretion systems, a separate translocator protein (TpsB; see the figure) mediates the secretion of the effector protein (TpsA) through the outer membrane. Over 700 proteins with functions that include auto-aggregation, adherence, invasion, cytotoxicity, serum resistance, cellto-cell spread and proteolysis use these two secretion systems to cross both inner and outer membranes during a simple two-step process ${ }^{124,125}$.

\section{Type VI secretion}


Type VI secretion systems (T6SSs; not shown in the figure) are recently discovered secretion systems that are found in several pathogens such as $P$. aeruginosa, enteroaggregative E. coli, S. Typhimurium, Vibrio cholerae and Yersinia pestis. T6SSs are multi-component systems that could be composed of 12 to 25 subunits. So far, little is known about their architecture and function (for reviews, see REFS 126,127).

Depending on function, three groups can be defined within the T4SS family (FIG. 1). First, T4SSs can mediate the conjugative transfer of plasmid DNA or transposons into a wide range of bacterial species ${ }^{1-3}$. At least two Gram-negative species, Escherichia coli and Agrobacterium tumefaciens, can deliver DNA substrates into fungal, plant or human cells $^{4-6}$. Conjugation promotes bacterial genome plasticity and the adaptive response of bacteria to changes in the environment. In particular, conjugation contributes to the spread of antibiotic resistance genes among pathogenic bacteria, leading to the emergence of multidrug-resistant pathogenic strains in health care settings. Second, in some Gramnegative bacteria, such as Helicobacter pylori and Neisseria gonorrhoeae, T4SSs mediate DNA uptake from and release into the extracellular milieu, further promoting genetic exchange ${ }^{7,8}$. Third, T4SSs deliver effector macromolecules into eukaryotic cells during the course of infection. For example, in pathogenic Gram-negative bacteria, including H. pylori, Brucella suis and Legionella pneumophila, T4SSs mediate the injection of virulence proteins into mammalian host cells ${ }^{9-11}$. In A. tumefaciens, the VirB/D T4SS delivers oncogenic DNA and proteins into plant cells, and Bordetella pertussis uses a T4SS to secrete pertussis toxin into the extracellular milieu. Sometimes, a single bacterial genome can encode multiple T4SSs: in H. pylori, for example, an effector protein delivery system (encoded by the cag pathogenicity island) coexists with a DNA release and uptake system (encoded by the $\operatorname{comB}$ gene cluster) $)^{7,10}$.

Despite the wide diversity of their substrates and functions, all T4SSs are evolutionarily related ${ }^{12,13}$. They share several components and probably function in a similar manner. The genes encoding the T4SS components are usually arranged in a single or a few operons. Although variations exist, many of the T4SSs found in Gram-negative bacteria are similar to the A. tumefaciens VirB/D T4SS, which comprises 12 proteins, named VirB1 to VirB11 and VirD4. T4SSs that have additional or missing components seem to have retained a core VirB/D-like subcomplex.

In general (but not always), T4SSs include an extracellular pilus that is composed of a major (VirB2) and a minor (VirB5) subunit. Three ATPases, VirB4, VirB11 and VirD4, power substrate secretion and possibly assist in the assembly of the system. Biochemical and functional data suggest that the inner membrane channel is composed of the polytopic membrane protein VirB6 and the bitopic membrane proteins $\underline{\text { VirB8 }}$ and VirB10. At the outer membrane, the composition of the pore that allows the substrate to reach the extracellular milieu is unknown; VirB9 in complex with the short lipoprotein VirB7 could be part of this structure. However, no transmembrane region has been found or is predicted in either protein. The function of VirB1 and $\underline{\operatorname{VirB} 3}$ in this complex is also unclear.

The lack of knowledge concerning the assembly, shape and structure of this complex multiprotein machine has spurred a major effort to characterize the three-dimensional structure of T4SSs. Indeed, the crystallization of the first T4SS component, the H. pylori VirB11 homologue, 10 years ago ushered in a new phase in type IV secretion (T4S) research, which has recently gained momentum with the first structural characterization of a large T4SS assembly, the core complex of the T4SS that is encoded by the conjugation plasmid pKM101. In this Review, we describe the successes of T4SS structural biology research over the past decade and discuss the insights that have been gained from these efforts. 


\section{The cytoplasmic ATPases}

T4SSs usually have three dedicated ATPases that form the power units of the secretion machinery. In A. tumefaciens, these ATPases are named VirD4, VirB11 and VirB4. All three are essential for secretion, and VirB11 and VirB4 are also required for biogenesis of the T4S pilus (which is known as the T-pilus in A. tumefaciens).

\section{VirD4 coupling protein}

Proteins related to VirD4 are ubiquitous members of the conjugative T4SSs that are found in Gram-negative and Gram-positive bacteria. These proteins are termed coupling proteins (CPs) or substrate receptors because their fundamental function is to recruit substrates to the T4SS for secretion through the translocation channel. CPs interact directly with T4SS substrates, presumably through binding secretion signal sequences, and mediate the transfer of these substrates to specific subunits of the secretion channel ${ }^{14}$. Some effector translocation systems, such as the T4SSs of B. pertussis or Brucella spp., use a CPindependent mechanism for substrate recruitment and secretion ${ }^{15-17}$. In these cases, translocation across the inner membrane is mediated either by another receptor that bears little or no sequence similarity to the CPs or by the general secretory pathway. In this pathway, the substrate is delivered to the periplasm by the SecYEG machinery, where it then engages with the T4S machine for translocation across the outer membrane.

CPs contain Walker A and B motifs, which are essential for nucleotide binding and hydrolysis ${ }^{18-20}$. Mutations in these motifs abolish translocation, indicating that nucleotide binding and hydrolysis are essential for the secretion process. ATPase activity has been reported for TrwB, the $\mathrm{CP}$ encoded by the $E$. coli IncW plasmid R388, and enzymatic activity is stimulated by single- and double-stranded DNA ${ }^{19-23}$.

CPs are tethered to the inner membrane by an amino-terminal membrane anchor sequence. For TrwB, this membrane anchor is required for oli-gomerization ${ }^{19,21,24}$. The X-ray structure of the soluble, $\sim 50 \mathrm{kDa}$ cytoplasmic domain of TrwB revealed a globular hexameric assembly in which each subunit has the shape of an orange segment and is composed of two distinct domains ${ }^{18}$ (FIG. 2a): an all-a-domain that faces the cytoplasm and a nucleotide-binding domain that is linked to the inner membrane by the $\mathrm{N}$-terminal membrane anchor. The all-a-domain contains seven helices and the nucleotide-binding domain is composed of a central twisted $\beta$-sheet flanked by several helices on both sides. The six TrwB protomers assemble to form a globular ring that is $\sim 110 \AA$ in diameter and 90 $\AA$ in height, with a $\sim 20 \AA$-wide channel in the centre. This channel forms an $8 \AA$-wide constriction at the cytoplasmic pole of the molecule. Binding pockets at the interface between the subunits form the nucleotide-binding sites. TrwB undergoes conformational changes in the central channel on substrate binding and hydrolysis ${ }^{25}$, suggesting that CPs might act as motor proteins during secretion.

\section{VirB11}

VirB11 belongs to a family of ATPases termed 'traffic ATPases', which are associated with Gram-negative bacterial type II, type III, type IV and type VI secretion systems ${ }^{14,26-28}$. VirB11-like ATPases are peripheral inner membrane proteins that might be in a dynamic and regulated equilibrium between the cytoplasm and the membrane ${ }^{29,30}$. Although VirB11 proteins display ATPase activity on their own, this activity can be stimulated by their interaction with membrane lipids, suggesting that their association with the membrane is biologically relevant ${ }^{31,32}$. 
Electron microscopy visualization of VirB11 homologues showed hexameric rings of $\sim 100$ $120 \AA$ in diameter 29,31 . The crystal structure of the ADP-bound VirB11 homologue of the $H$. pylori Cag T4SS, HP0525, revealed that each monomer consists of two domains formed by the $\mathrm{N}$ - and carboxy-terminal halves of the protein ${ }^{33,34}$ (FIG. 2a). The nucleotide-binding site is at the interface between the two domains. In the hexamer, the $\mathrm{N}$ - and $\mathrm{C}$-terminal domains (NTD and CTD) form two separate rings that define a chamber of $\sim 50 \AA$ in diameter, which is open on the NTD side and closed on the CTD side. The CTD adopts a RecA-like fold, and the NTD fold is unique to HP5025. Recently, the structure of B. suis VirB11 was determined $^{35}$. The $B$. suis VirB11 monomer differs dramatically from that of HP0525 owing to a large domain swap that is caused by the insertion of additional sequences into the linker sequence between the NTD and the CTD. The overall assembly of the VirB11 hexamer remains similar to that of HP5025, but the domain organization markedly modifies the nucleotide-binding site and the interface between subunits ${ }^{35}$. Based on sequence comparisons, it is likely that most VirB11 homologues display a B. suis VirB11-like architecture. The importance of this domain swap is unclear.

Biochemical and structural studies have provided a detailed view of the dynamics of VirB11 (REF. 33). In the absence of nucleotide, the CTD ring remains unchanged and maintains the subunit-subunit contacts in the hexameric structure, whereas the NTDs are flexible and display various rigid-body conformations that render the NTD ring asymmetric. The binding of three ATP molecules induces a movement of three NTDs into a rigid conformation, and the concomitant hydrolysis of these ATP molecules and binding of three other molecules in the nucleotide-free subunits locks the hexamer into a compact and symmetrical structure. When all the nucleotides are hydrolysed and released, the structure is relaxed and the VirB11 hexamer returns to its nucleotide-free state.

\section{VirB4}

VirB4 proteins are associated with conjugative T4SSs in both Gram-positive and Gramnegative bacteria ${ }^{1,14}$. The VirB4 homologues contain conserved Walker A and B motifs, which are essential for the secretion process ${ }^{36-40}$. The ATPase activity of purified VirB4like proteins has been difficult to demonstrate in vitro, although there are two reports of such activities, namely for A. tumefaciens VirB4 and for TrwK of E. coli, encoded by plasmid R388 (REFS 40,41).

Differences have been reported in the subcellular localization and oligomeric state of the few characterized VirB4 proteins. VirB4 homologues have from zero to four predicted transmembrane segments (TMSs) ${ }^{26,40,42,43}$. In A. tumefaciens, VirB4 associates tightly with the inner membrane, and experimental evidence suggests that one or two domains are embedded into or protrude across the membrane ${ }^{38}$. By contrast, TrwK is soluble. The oligomeric state of the biologically active form of VirB4 has not been established. A. tumefaciens VirB4 forms homodimers, but the dimer might represent a building block for the assembly of higher-order complexes ${ }^{43,44}$. E. coli TrwK is predominantly purified as a monomer, but the catalytically active form seems to assemble as higher-order complexes that are thought to correspond to homohexamers ${ }^{39,40}$. The oligomeric state of VirB4 proteins might vary depending on membrane association, ATP binding or hydrolysis, and interactions with other T4S machine subunits.

\section{Biochemical and functional interactions}

In A. tumefaciens, all three ATPases - VirD4, VirB4 and VirB11 — interact with each other ${ }^{45-49}$ (FIG. 3). Therefore, they are likely to form a large ATPase complex that energizes substrate transport through the translocation machinery. The architecture of this complex and the contributions of each ATPase to secretion or pilus biogenesis are still 
unclear.VirB10 interacts directly with VirB4 and VirD4 (REFS 46,48-51). The VirB10VirD4 interaction involves domains near the $\mathrm{N}$-terminal regions of both proteins that reside within or near the inner membrane $e^{50-52}$.

\section{The translocation pore complex}

Defining the architecture of the T4S channel has been an area of intensive investigation. A recent breakthrough showed that a double-membrane-spanning, $1 \mathrm{MDa}$ channel complex can be assembled from homologues of the A. tumefaciens VirB7, VirB9 and VirB10 proteins $^{53}$.

\section{The VirB7-VirB9-VirB10 core complex}

The T4S core complex, encoded by the conjugative plasmid pKM101, is composed of 14 copies each of the VirB7, VirB9 and VirB10 homologue proteins ${ }^{53}$. The structure of the complex was determined at $15 \AA$ resolution using cryoelectron microscopy; it is a cylindrical structure of $185 \AA$ in diameter and $185 \AA$ in length that is composed of two layers termed I and O layers that are linked by thin stretches of electron density (FIG. 4). Each layer forms a double-walled, ring-like structure that defines a hollow chamber inside the complex. The I layer is composed of the N-terminal domains of the VirB9 and VirB10 homologues and is anchored in the inner membrane, resembling a cup that is opened at the base by a $55 \AA$ diameter hole. The O layer consists of a main body and a narrower cap on the outermost side of the complex. It is inserted in the outer membrane and is composed of the VirB7 homologue and the CTDs of the VirB9 and VirB10 homologues (FIG. 4). A narrow hole in the cap allows communication between the chamber in the $\mathrm{O}$ layer and the extracellular milieu; however, this opening (10 ̊ in diameter) is too small to let substrates out.

VirB10 is a bitopic membrane protein that is inserted in the bacterial inner membrane ${ }^{52,54}$. It consists of a short N-terminal cytoplasmic region, a single $\mathrm{TMS}^{54}$, a proline-rich region and a large $\mathrm{C}$-terminal periplasmic domain. This domain consists of an altered $\beta$-barrel flanked by a helix lying on its side (the a 1 helix) and a flexible helix-turn-helix antenna of $70 \AA$ in length that projects away from the $\beta$-barrel ${ }^{55}$ (FIG. 2b). A recent mutational analysis showed that the antenna projection and the $\alpha 1$ helix can be removed without affecting core complex assembly or secretion efficiency, but it does severely affect T-pilus biogenesis. The prolinerich region is essential for core complex assembly and substrate secretion ${ }^{52}$.

VirB7 and VirB9 contain signal peptides that target them to the periplasm. VirB7 is a small lipoprotein that is inserted in the outer membrane and interacts with and stabilizes VirB9; in A. tumefaciens, a disulphide bridge is formed between the two proteins. VirB9 consists of two domains linked by a flexible linker of $\sim 50$ amino acids ${ }^{56,57}$. In the VirB7-VirB9VirB10 complex, the CTD of VirB9 is part of the structure that forms the outer membrane pore. However, it can be produced as a soluble complex with VirB7, the structure of which has been solved by nuclear magnetic resonance spectroscopy: in solution, the VirB9 Cterminal domain adopts a $\beta$-sandwich fold, around which VirB7 winds ${ }^{57}$ (FIG. 2b).

The VirB10 CTD crystal structure could be fitted into the electron density of the external wall of the main body of the $\mathrm{O}$ layer, with its $\mathrm{N}$ terminus directed towards the I layer (FIG. 4). In this location, VirB10 would form a scaffold, bridging the inner membrane and the outer membrane components of the core complex ${ }^{58}$. By contrast, the structure of the VirB9 CTD in solution could not be fitted into the electron density. The VirB9 C-terminal domain structure displays a protruding, three-stranded $\beta$-appendage opposite the VirB9-VirB7 interface (shown in red in FIG. 2b). This $\beta$-appendage loosely associates with the VirB9 $\beta$ sandwich core structure, and biochemical data have shown that the equivalent region in $A$. 
tumefaciens is exposed on the cell surface. Therefore, the region of VirB9 that is most likely to be inserted in the outer membrane is the $\beta$-appendage. This region can indeed undergo a large conformational change to protrude out of the cell ${ }^{57}$, similarly to the pre-stem $\beta$ appendage of a-haemolysin, which in the presence of a lipid bilayer undergoes a large conformational change that leads to its projection through the outer membrane and its heptamerization to form a 14 -strand $\beta$-barrel ${ }^{59,60}$.

\section{Where do VirB6 and VirB8 fit?}

The I layer of the T4S complex, which is composed of the NTDs of VirB9 and VirB10, is inserted in the inner membrane by the VirB10 N-terminal TMS. However, it is unlikely that the 14 VirB10 TMSs would be sufficient to form the inner membrane pore. Among the T4SS subunits, VirB6 and VirB8 are better candidates to form this pore as, unlike VirB10, they directly contact the substrate during secretion in A. tumefaciens ${ }^{61}$ (FIG. 5).

The VirB8 subunit is a bitopic inner membrane protein that is composed of an N-terminal TMS and a large periplasmic $\mathrm{CTD}^{54,55,62}$. This protein is thought to function in the nucleation of the T4SS channel ${ }^{63-65}$ and in pilus biogenesis ${ }^{44}$. VirB8 also participates directly in substrate secretion ${ }^{61}$. The crystal structures of the periplasmic domains of $B$. suis and A. tumefaciens VirB8 (REFS 55,66) display similar globular structures that comprise an extended $\beta$-sheet flanked by five $a$-helices ${ }^{55,66}$ (FIG. $2 b$ ).

VirB6 is a polytopic inner membrane protein that is essential for substrate secretion through the inner membrane ${ }^{61}$. H. pylori ComB6 and A. tumefaciens VirB6 have a similar structure, with a periplasmic $\mathrm{N}$ terminus, five TMSs and a cytoplasmic $\mathrm{CTD}^{67,68}$. Both proteins also have a central region composed of a large periplasmic loop (the P2 loop), which in $A$. tumefaciens mediates the interaction between VirB6 and the substrate, T-DNA (FIG. 5). The other regions of the proteins are essential for substrate transfer from VirB6 to VirB8 in the periplasm or to VirB2 and VirB9 at the outer membrane ${ }^{68}$. These data indicate that VirB6 is probably a central component of the inner membrane channel.

VirB6 and VirB8 interact with the outer membrane components VirB7 and VirB9 (REFS 63,69-72) (FIG. 3). Surprisingly, no physical interaction has been observed between VirB6 and VirB8, even though these proteins seem to interact functionally (see below). VirB8 has also been shown to interact with VirB1, VirB4, VirB5 and VirB11 (REFS 44,45,48,73,74) (FIG. 3). On the basis of the VirB protein interaction network that has been discovered so far, it is tempting to propose that the minimal T4SS inner membrane pore consists of VirB4, VirB6 and VirB8, each docked in the $55 \AA$ opening at the base of the VirB7-VirB9-VirB10 core complex.

\section{VirB1 and VirB3: orphan proteins?}

The evidence suggests that VirB1 and possibly VirB3 are not part of the secretion apparatus itself but instead contribute in distinct ways to the formation of the T4S machine. VirB1 is a periplasmic protein ${ }^{75}$ that harbours a lysozyme-like structural fold ${ }^{76}$. It belongs to a large superfamily of proteins that are associated with bacterial surface structures, such as type II and type III secretion systems, type IV pili (not to be confused with T4S pili), DNA uptake systems, flagella and bacteriophage entry systems. In all of these systems, associated lytic transglycosylase subunits are proposed to punch holes in the peptidoglycan cell wall to allow the assembly of the surface structures. Deletion of virB1 reduces but does not abolish secretion in A. tumefaciens; however, it does abolish T-pilus biogenesis ${ }^{77-80}$. VirB1 is proteolytically processed into two halves, each of which contributes to T4SS assembly or function ${ }^{81}$. The NTD of VirB1, which carries the muraminidase activity, resides in the 
periplasm, where it presumably degrades peptidoglycans. The CTD, known as VirB1*, is secreted into the extracellular milieu ${ }^{81}$ and might promote T-pilus biogenesis ${ }^{82}$.

VirB3 is a small protein that is predicted to contain one or two TMSs near its $\mathrm{N}$ terminus. The localization of VirB3 is unclear, with reports placing it in either the inner or the outer membrane ${ }^{2,41,83,84}$. Interestingly, chimeric VirB3-VirB4 proteins have been identified in several T4SSs, including the Campylobacter jejuni $\mathrm{T}_{4} \mathrm{SS}^{85}$. These observations suggest that VirB3 might reside in the inner membrane and form a functional complex with VirB4 (REF. 14). The exact contribution of VirB3 to channel or T-pilus assembly is not known.

\section{The pilus and other T4SS surface structures}

Most T4SS gene clusters in Gram-negative bacteria encode a small protein that bears discernible sequence similarity to the TraA pilin (encoded by the E. coli $\mathrm{F}$ plasmid) and the VirB2 pilin of A. tumefaciens. In these systems, T4SS pilin expression is essential for secretion ${ }^{86,87}$. Pili might help to establish a stable and specific contact between donor and target cells. In addition, they might serve as channels for the passage of T4S substrates between donor and recipient or host cells. Whether the T4S substrate passes through the hollow lumen of the T4S pilus remains controversial. Nevertheless, recent observations have shown that DNA can be transferred between cells that are not in direct contact during conjugation ${ }^{88}$ and that DNA can be detected within the F-pilus ${ }^{89}$. Furthermore, in H. pylori, CagA (a T4SS substrate) can be found at the tip of pili ${ }^{90}$. However, it is interesting to note that pilus production and substrate secretion in some T4SSs are clearly distinct events. Mutations in the pilin subunit ${ }^{91}$ or in several T4SS components (VirB6, VirB9 and VirB11 in A. tumefaciens ${ }^{56,68,92}$ ) abolish the production of detectable amounts of pilus without affecting substrate translocation. Isolation of these 'uncoupling' mutations established that assembly of wild-type T-pili is not required for secretion.

\section{T4SS pilins}

All T4SS pilins that have been characterized undergo several processing reactions during maturation. The propilins are first targeted to the inner membrane by an unusually long ( $\sim 30-50$ amino acid residue) signal peptide that is cleaved by a dedicated protease ${ }^{93-95}$. Additional maturation steps depend on the type of pilin and can be separated into two classes. Most F-like pilins (also known as IncF-like pilins; subunits of the conjugative pili that are produced by the IncF, IncH, IncT and IncJ systems) are acetylated at the $\mathrm{N}$ terminus and inserted in the inner membrane ${ }^{96}$. By contrast, the P-like (also known as IncP-like) conjugative pilins, exemplified by $\mathrm{TrbC}$ from the IncP plasmid RP4 and VirB2 from A. tumefaciens, are proteolytically processed at one or both of their termini and then the $\mathrm{N}$ and $\mathrm{C}$ termini are covalently joined in a head-to-tail cyclization reaction. In E. coli, the RP4encoded TraF protein catalyses the cyclization of TrbC, whereas in A. tumefaciens an unidentified chromosome-encoded protein seems to be responsible for VirB2 cyclization. Pilin homologues or orthologues in other T4SSs, including pertussis toxin liberation protein A (PtlA) of the B. pertussis Ptl T4SS and the VirB2s of the Brucella spp. VirB systems, might also undergo similar processing reactions before insertion into the inner membrane ${ }^{97,98}$.

In A. tumefaciens, VirB5 is a minor T-pilus component ${ }^{99-101}$. Homologues of VirB5 are found in many conjugative and effector translocation T4SSs. The crystal structure of the VirB5 homologue $\underline{\operatorname{TraC}}$, which is encoded by the E. coli pKM101 conjugative plasmid, comprises an elongated three-helix bundle flanked by a smaller globular region ${ }^{102}$ (FIG. 2b). Mutational studies of the structure of TraC suggest that it is an adhesin ${ }^{102}$; this is supported by the finding that in A. tumefaciens VirB5 localizes at the tip of the T-pilus ${ }^{103}$. Also, in $H$. pylori, $\underline{\text { CagL, a potential VirB5 homologue, might function as an adhesin }}{ }^{90,104}$. 


\section{Pilus morphology and structure}

The conjugative pili have been classified into two main groups on the basis of morphology. F-like pili are long $(2-20 \mu \mathrm{m})$, flexible appendages with a diameter of 8-9 $\mathrm{nm}$. P-like pili are short $(<1 \mu \mathrm{m})$, rigid rods with a diameter of $8-12 \mathrm{~nm}^{2},{ }^{105}$. The A. tumefaciens T-pilus has a diameter of $10 \mathrm{~nm}$ but is flexible and variable in length ${ }^{97}$. In addition to harbouring a VirB2-like pilin, which presumably assembles pili ${ }^{106}$, H. pylori harbours $100-200 \mathrm{~nm}$ long, sheathed appendages composed of a large variant of VirB10, known as HP0527 (REFS 107,108).

The structure of the F-pilus was recently examined using cryoelectron microscopy and single particle methods ${ }^{109}$. The tubular structure has a central lumen of $\sim 30 \AA$ and a diameter of $\sim 85 \AA$. Two different subunit packing arrangements were observed: a stack of pilin rings of $\mathrm{C} 4$ symmetry and a one-start helical symmetry with an axial rise of $\sim 3.5 \AA$ per subunit and a pitch of $\sim 12.2 \AA$. These two packing arrangements seem to coexist in the pilus structure. The lumen diameter is large enough to accommodate single-stranded DNA but not sufficiently large to afford passage of the F-pilus conjugative transfer relaxase TraI, which is covalently attached to the DNA and has a molecular mass of $\sim 200 \mathrm{kDa}$. Unless it is unfolded, it is unlikely that TraI would translocate through the pilus lumen.

\section{Mechanism of T4SS assembly}

Taking into account subunit topologies and structures as well as the network of subunitsubunit interactions, it is possible to propose a model for the assembly of a functional VirB/ D T4S apparatus. We propose that first, VirB7, VirB9 and VirB10 assemble to form a stable core complex that spans the cell envelope. Subsequently, VirB6 and VirB8 and then the ATPase complex - VirB4 (possibly bound to VirB3), VirB11 and VirD4 - dock onto the core complex to complete the translocation channel at the inner membrane. The VirB2 and VirB5 pilus subunits are then recruited to build either the distal portion of the secretion channel or the T-pilus (FIG. 6).

A combination of ultrastructural and biochemical data support this proposed assembly pathway. On the basis of observed stabilizing interactions ${ }^{86}$, it has been suggested that channel assembly initiates with formation of the core complex across the cell envelope. Comprising VirB7, VirB9 and VirB10, this core complex assembles spontaneously, without energy requirements ${ }^{52,53}$. Although VirB7 lipidation is essential for secretion ${ }^{110}$, it is not required for core complex assembly ${ }^{53}$. VirB7 lipidation is important for the correct insertion of the core complex into the outer membrane ${ }^{53}$. As noted above, VirB6 and VirB8 interact functionally and physically with VirB7 and VirB9 and probably also with VirB10 (FIG. 3). Interestingly, however, when VirB8 is expressed with VirB7, VirB9 and VirB10, it is not recruited to the core complex ${ }^{53}$. VirB6 and VirB4 might therefore be necessary for the stabilization of VirB8 and its incorporation into the core complex ${ }^{44}$. To complete its assembly, the translocation pore would then recruit VirB2 and VirB5 (REF. 44).

The assembly of the translocation pore across the cell envelope is likely to be a concerted process that is regulated spatially and temporally by as-yet-unknown proteins or lipids that mediate the assembly process at specific sites in the cell envelope ${ }^{111}$. The A. tumefaciens VirB/D system, for example, assembles at cell poles, and VirB8 is implicated in directing machine assembly at these sites ${ }^{58}$. VirB8 might therefore coordinate the spatial positioning of the VirB7-VirB9-VirB10 core complex as an additional early step in the morphogenetic pathway.

The T4S apparatus is generally depicted as a protein complex that is used for substrate secretion and T4S pilus biogenesis. However, accumulating evidence supports the idea of a 
bifurcation in T4SS assembly once the translocation pore has been assembled ${ }^{14}$. Evidence favouring this late-stage bifurcation includes the findings that VirD4 is dispensable for pilus biogenesis but required for substrate secretion ${ }^{77,107}$. By contrast, VirB1 is exclusively required for T-pilus biogenesis but not secretion channel formation ${ }^{79,82}$. Finally, as noted above, mutations in conjugative pilin subunits or other T4SS components block T-pilus assembly but allow wild-type levels of substrate transfer. The sequence of events leading to the assembly of the T-pilus is still fundamentally unknown ${ }^{44,82}$. However, it is important to note that, even if pilus formation is not necessary for secretion to occur, association of VirB2 and VirB5 with the translocation pore is required (see below).

\section{Mechanism of substrate translocation}

Seminal insights into the substrate translocation pathway through the A. tumefaciens VirB/D T4SS have been obtained recently ${ }^{61}$. It was shown that the T-DNA makes sequential contacts with VirD4, VirB11, VirB6, VirB8, VirB9 and then VirB2 (FIG. 5). The other components of the T4SS do not interact with the T-DNA but are essential for substrate transfer at different steps.

VirD4 is the first component to contact the substrate; this is consistent with its role as the substrate receptor at the gate of the secretion apparatus. Neither ATP hydrolysis nor other T4SS components are required for VirD4 to interact with its substrate ${ }^{49,112}$. VirD4 transfers the substrate to VirB11. This transfer could not be detected when VirB7 was deleted, highlighting the essential role of this lipoprotein in mediating the formation of the core complex early during machine assembly. Mutations in the Walker A motifs in VirD4 and VirB11do not affect this substrate translocation step, suggesting that the delivery of substrate from VirD4 to VirB11 does not require energy ${ }^{49}$.

VirB11 delivers the T-DNA substrate to the inner membrane subunits VirB6 and VirB8. These proteins seem to function together, as deletion of each one blocks substrate translocation ${ }^{49,61}$. Presumably, this step reflects the passage of the substrate through the VirB6-VirB8-VirB10 inner membrane channel complex. Each of the T4SS ATPases, VirB4, VirB11 and VirD4, must be present and catalytically active for substrate transfer from VirB11 to the presumptive inner membrane channel complex to occur.

Finally, the substrate is transferred across the periplasm to the outer membrane-associated proteins VirB2 and VirB9. VirB3, VirB5 and VirB10 are essential for this process, although the exact roles of VirB3 and VirB5 are unknown. As noted above, VirB10 is a structural scaffold that bridges the inner and outer membrane assemblies ${ }^{52,53}$. In addition, VirB10 senses ATP hydrolysis by VirB11 and VirD4 at the inner membrane and, in turn, undergoes a conformational change that is necessary for substrate transfer across the periplasm to VirB2 and VirB9, perhaps by opening the outer membrane cap of the core complex. The substrate might cross the periplasm through a filament composed of the VirB2 pilin, which is assembled within the chamber of the VirB7-VirB9-VirB10 core. Alternatively, the substrate might pass through the core complex and interact with the pilin at the outer face of the outer membrane.

\section{Conclusions and future directions}

Recent progress in elucidating the structural biology of T4SSs has provided the first glimpse of the inner shell of these complex multiprotein machines ${ }^{53}$. This core complex is likely to be the scaffold around which the other T4SS components organize. Once the inner-outer membrane channel is completed by the addition of VirB6 and VirB8, further build-up of the machinery may follow two distinct but not necessarily mutually exclusive routes: one 
leading to pilus biogenesis and another leading to secretion. A formidable challenge for the years to come will be to characterize the structures of these complexes.

The role of the ATPases in T4SSs also remains to be clarified. VirD4 clearly acts as a receptor, bringing substrates to the translocation apparatus. VirD4 might also act as a molecular motor to deliver the substrate through the system. VirB11 and VirB4 are needed for substrate transfer across the inner membrane, probably functioning in a coordinated manner with VirD4. However, both VirB ATPases, but not VirD4, are essential for the assembly of the T4S pilus. How the VirB ATPases coordinate their activities with VirD4 to mediate substrate transfer and function independently of VirD4 to direct pilus assembly is fundamentally unknown. It is also noteworthy that a few T4SSs in Gram-negative bacteria and nearly all T4SSs in Gram-positive bacteria lack VirB11 homologues, whereas VirB4 is almost invariably a signature subunit of T4SSs in all species. Therefore, VirB4 is likely to have a fundamental role in powering the assembly or function of the T4SS. Further investigations will need to clarify how the ATPases not only contribute to the assembly of the secretion channel and the conjugative pilus, but also interact with and move substrates through the channel.

Finally, the role and function of the pilus itself remain unresolved. Does the pilus serve as an attachment device, as a conduit for substrates or as both? If, as envisaged above, two types of T4S complex are formed, one dedicated to secretion and the other to pilus biogenesis, then they might be able to transition from one to the other: transition from a pilus biogenesis-competent assembly to one that is secretion competent would only require depolymerization of the pilus. Such an activity has been shown in the F-plasmid system ${ }^{2},{ }^{113}$. In other secretion systems, notably type II secretion systems, cycles of polymerization and depolymerization are thought to be crucial for substrate secretion ${ }^{114}$. Whether the pilin has a similarly active role in secretion remains to be shown, but at this stage this possibility cannot be excluded.

\section{Acknowledgments}

This work was funded by Wellcome Trust grant 082227 to G.W. and National Institutes of Health grant GM48746 to P.J.C.

\section{Glossary}

\section{General secretory pathway \\ Walker A and $B$ motif}

T-DNA

Type IV pilus
The pathway in which substrates are targeted and secreted through the Sec machinery

A Walker A motif is an amino acid motif (GXXXGKT, in which X denotes any amino acid residue) that is involved in the nucleotide binding that occurs in many ATP-requiring enzymes. A Walker B motif is also a conserved sequence (usually XXXXD, in which X denotes any hydrophobic amino acid residue) that is used in conjunction with the Walker A motif to hydrolyse ATP

One of the substrates of the T4SS encoded by the Vir system of Agrobacterium tumefaciens. T-DNA is encoded by the A. tumefaciens Ti plasmid and is essential for A. tumefaciens pathogenesis

An elongated, flexible appendage that extends from the surface of Gramnegative bacterial cells and is used for adhesion and for cell motility (twitching motility) 
F-pilus

Relaxase
The pilus formed by the T4SS that is encoded by the F plasmid

A protein that targets the origin of the transfer sequence on plasmid DNA. Along with other proteins, it targets the DNA to the T4SS

\section{References}

1. Grohmann E, Muth G, Espinosa M. Conjugative plasmid transfer in Gram-positive bacteria. Microbiol Mol Biol Rev. 2003; 67:277-301. [PubMed: 12794193]

2. Lawley TD, Klimke WA, Gubbins MJ, Frost LS. F factor conjugation is a true type IV secretion system. FEMS Microbiol Lett. 2003; 224:1-15. [PubMed: 12855161]

3. Trieu-Cuot P, Gerbaud G, Lambert T, Courvalin P. In vivo transfer of genetic information between Gram-positive and Gram-negative bacteria. EMBO J. 1985; 4:3583-3587. [PubMed: 3937729]

4. Bundock P, den Dulk-Ras A, Beijersbergen A, Hooykaas PJ. Trans-kingdom T-DNA transfer from Agrobacterium tumefaciens to Saccharomyces cerevisiae. EMBO J. 1995; 14:3206-3214. [PubMed: 7621833]

5. Heinemann JA, Sprague GF Jr. Bacterial conjugative plasmids mobilize DNA transfer between bacteria and yeast. Nature. 1989; 340:205-209. [PubMed: 2666856]

6. Waters VL. Conjugation between bacterial and mammalian cells. Nature Genet. 2001; 29:375-376. [PubMed: 11726922]

7. Smeets LC, Kusters JG. Natural transformation in Helicobacter pylori: DNA transport in an unexpected way. Trends Microbiol. 2002; 10:159-162. [PubMed: 11912014]

8. Hamilton HL, Dillard JP. Natural transformation of Neisseria gonorrhoeae: from DNA donation to homologous recombination. Mol Microbiol. 2006; 59:376-385. [PubMed: 16390436]

9. Corbel MJ. Brucellosis: an overview. Emerg Infect Dis. 1997; 3:213-221. [PubMed: 9204307]

10. Backert S, Meyer TF. Type IV secretion systems and their effectors in bacterial pathogenesis. Curr Opin Microbiol. 2006; 9:207-217. [PubMed: 16529981]

11. Ninio S, Roy CR. Effector proteins translocated by Legionella pneumophila: strength in numbers. Trends Microbiol. 2007; 15:372-380. [PubMed: 17632005]

12. Lessl M, Balzer D, Pansegrau W, Lanka E. Sequence similarities between the RP4 Tra2 and the Ti VirB region strongly support the conjugation model for T-DNA transfer. J Biol Chem. 1992; 267:20471-20480. [PubMed: 1400366]

13. Lessl M, Lanka E. Common mechanisms in bacterial conjugation and Ti-mediated T-DNA transfer to plant cells. Cell. 1994; 77:321-324. [PubMed: 8181052]

14. Christie PJ, Atmakuri K, Krishnamoorthy V, Jakubowski S, Cascales E. Biogenesis, architecture, and function of bacterial type IV secretion systems. Annu Rev Microbiol. 2005; 59:451-485. [PubMed: 16153176]

15. Burns DL. Type IV transporters of pathogenic bacteria. Curr Opin Microbiol. 2003; 6:29-34. [PubMed: 12615216]

16. Seubert A, Hiestand R, de la Cruz F, Dehio C. A bacterial conjugation machinery recruited for pathogenesis. Mol Microbiol. 2003; 49:1253-1266. [PubMed: 12940985]

17. O'Callaghan D, et al. A homologue of the Agrobacterium tumefaciens VirB and Bordetella pertussis Ptl type IV secretion systems is essential for intracellular survival of Brucella suis. Mol Microbiol. 1999; 33:1210-1220. [PubMed: 10510235]

18. Gomis-Ruth FX, et al. The bacterial conjugation protein TrwB resembles ring helicases and F1ATPase. Nature. 2001; 409:637-641. This study reports the crystal structure of a VirD4 family protein, providing key insights into the molecular mechanisms of $\mathrm{CP}$ proteins. [PubMed: 11214325]

19. Moncalian G, et al. Characterization of ATP and DNA binding activities of TrwB, the coupling protein essential in plasmid R388 conjugation. J Biol Chem. 1999; 274:36117-36124. [PubMed: 10593894] 
20. Schroder G, Lanka E. TraG-like proteins of type IV secretion systems: functional dissection of the multiple activities of TraG (RP4) and TrwB (R388). J Bacteriol. 2003; 185:4371-4381. [PubMed: 12867445]

21. Schroder G, et al. TraG-like proteins of DNA transfer systems and of the Helicobacter pylori type IV secretion system: inner membrane gate for exported substrates? J Bacteriol. 2002; 184:27672779. [PubMed: 11976307]

22. Tato I, Zunzunegui S, de la Cruz F, Cabezon E. TrwB, the coupling protein involved in DNA transport during bacterial conjugation, is a DNA-dependent ATPase. Proc Natl Acad Sci USA. 2005; 102:8156-8161. [PubMed: 15919815]

23. Tato I, et al. The ATPase activity of the DNA transporter TrwB is modulated by protein TrwA: implications for a common assembly mechanism of DNA translocating motors. J Biol Chem. 2007; 282:25569-25576. [PubMed: 17599913]

24. Hormaeche I, et al. Purification and properties of TrwB, a hexameric, ATP-binding integral membrane protein essential for R388 plasmid conjugation. J Biol Chem. 2002; 277:46456-46462. [PubMed: 12244053]

25. Gomis-Ruth FX, Moncalian G, de la Cruz F, Coll M. Conjugative plasmid protein TrwB, an integral membrane type IV secretion system coupling protein. Detailed structural features and mapping of the active site cleft. J Biol Chem. 2002; 277:7556-7566. [PubMed: 11748238]

26. Cao TB, Saier MH Jr. Conjugal type IV macromolecular transfer systems of Gram-negative bacteria: organismal distribution, structural constraints and evolutionary conclusions. Microbiology. 2001; 147:3201-3214. [PubMed: 11739753]

27. Filloux A. The type VI secretion system: a tubular story. EMBO J. 2009; 28:309-310. [PubMed: 19225443]

28. Planet PJ, Kachlany SC, DeSalle R, Figurski DH. Phylogeny of genes for secretion NTPases: identification of the widespread tadA subfamily and development of a diagnostic key for gene classification. Proc Natl Acad Sci USA. 2001; 98:2503-2508. [PubMed: 11226268]

29. Krause S, et al. Sequence-related protein export NTPases encoded by the conjugative transfer region of RP4 and by the cag pathogenicity island of Helicobacter pylori share similar hexameric ring structures. Proc Natl Acad Sci USA. 2000; 97:3067-3072. [PubMed: 10716714]

30. Rashkova S, Spudich GM, Christie PJ. Characterization of membrane and protein interaction determinants of the Agrobacterium tumefaciens VirB11 ATPase. J Bacteriol. 1997; 179:583-591. [PubMed: 9006008]

31. Krause S, Pansegrau W, Lurz R, de la Cruz F, Lanka E. Enzymology of type IV macromolecule secretion systems: the conjugative transfer regions of plasmids RP4 and R388 and the cag pathogenicity island of Helicobacter pylori encode structurally and functionally related nucleoside triphosphate hydrolases. J Bacteriol. 2000; 182:2761-2770. [PubMed: 10781544]

32. Rivas S, Bolland S, Cabezon E, Goni FM, de la Cruz F. TrwD, a protein encoded by the IncW plasmid R388, displays an ATP hydrolase activity essential for bacterial conjugation. J Biol Chem. 1997; 272:25583-25590. [PubMed: 9325277]

33. Savvides SN, et al. VirB11 ATPases are dynamic hexameric assemblies: new insights into bacterial type IV secretion. EMBO J. 2003; 22:1969-1980. [PubMed: 12727865]

34. Yeo HJ, Savvides SN, Herr AB, Lanka E, Waksman G. Crystal structure of the hexameric traffic ATPase of the Helicobacter pylori type IV secretion system. Mol Cell. 2000; 6:1461-1472. This study reports the crystal structure of a VirB11 family protein and, together with reference 33, elucidates the nucleotide-dependent conformational changes that are required for its function. [PubMed: 11163218]

35. Hare S, Bayliss R, Baron C, Waksman G. A large domain swap in the VirB11 ATPase of Brucella suis leaves the hexameric assembly intact. J Mol Biol. 2006; 360:56-66. [PubMed: 16730027]

36. Berger BR, Christie PJ. The Agrobacterium tumefaciens virB4 gene product is an essential virulence protein requiring an intact nucleoside triphosphate-binding domain. J Bacteriol. 1993; 175:1723-1734. [PubMed: 8449880]

37. Cook DM, Farizo KM, Burns DL. Identification and characterization of PtlC, an essential component of the pertussis toxin secretion system. Infect Immun. 1999; 67:754-759. [PubMed: 9916087] 
38. Fullner KJ, Stephens KM, Nester EW. An essential virulence protein of Agrobacterium tumefaciens, VirB4, requires an intact mononucleotide binding domain to function in transfer of TDNA. Mol Gen Genet. 1994; 245:704-715. [PubMed: 7830718]

39. Rabel C, Grahn AM, Lurz R, Lanka E. The VirB4 family of proposed traffic nucleoside triphosphatases: common motifs in plasmid RP4 TrbE are essential for conjugation and phage adsorption. J Bacteriol. 2003; 185:1045-1058. [PubMed: 12533481]

40. Arechaga I, et al. ATPase activity and oligomeric state of TrwK, the VirB4 homologue of the plasmid R388 type IV secretion system. J Bacteriol. 2008; 190:5472-5479. [PubMed: 18539740]

41. Shirasu K, Koukolikova-Nicola Z, Hohn B, Kado CI. An inner-membrane-associated virulence protein essential for T-DNA transfer from Agrobacterium tumefaciens to plants exhibits ATPase activity and similarities to conjugative transfer genes. Mol Microbiol. 1994; 11:581-588. [PubMed: 8152380]

42. Draper O, Middleton R, Doucleff M, Zambryski PC. Topology of the VirB4 C terminus in the Agrobacterium tumefaciens VirB/D4 type IV secretion system. J Biol Chem. 2006; 281:3762837635. [PubMed: 17038312]

43. Dang TA, Christie PJ. The VirB4 ATPase of Agrobacterium tumefaciens is a cytoplasmic membrane protein exposed at the periplasmic surface. J Bacteriol. 1997; 179:453-462. [PubMed: 8990298]

44. Yuan Q, et al. Identification of the VirB4-VirB8-VirB5-VirB2 pilus assembly sequence of type IV secretion systems. J Biol Chem. 2005; 280:26349-26359. [PubMed: 15901731]

45. Ward DV, Draper O, Zupan JR, Zambryski PC. Peptide linkage mapping of the Agrobacterium tumefaciens vir-encoded type IV secretion system reveals protein subassemblies. Proc Natl Acad Sci USA. 2002; 99:11493-11500. [PubMed: 12177441]

46. Terradot L, et al. Biochemical characterization of protein complexes from the Helicobacter pylori protein interaction map: strategies for complex formation and evidence for novel interactions within type IV secretion systems. Mol Cell Proteomics. 2004; 3:809-819. [PubMed: 15133060]

47. Rain JC, et al. The protein-protein interaction map of Helicobacter pylori. Nature. 2001; 409:211215. [PubMed: 11196647]

48. Malek JA, et al. Protein interaction mapping on a functional shotgun sequence of Rickettsia sibirica. Nucleic Acids Res. 2004; 32:1059-1064. [PubMed: 14872061]

49. Atmakuri K, Cascales E, Christie PJ. Energetic components VirD4, VirB11 and VirB4 mediate early DNA transfer reactions required for bacterial type IV secretion. Mol Microbiol. 2004; 54:1199-1211. [PubMed: 15554962]

50. Llosa M, Zunzunegui S, de la Cruz F. Conjugative coupling proteins interact with cognate and heterologous VirB10-like proteins while exhibiting specificity for cognate relaxosomes. Proc Natl Acad Sci USA. 2003; 100:10465-10470. [PubMed: 12925737]

51. Gilmour MW, Lawley TD, Rooker MM, Newnham PJ, Taylor DE. Cellular location and temperature-dependent assembly of IncHI1 plasmid R27-encoded TrhC-associated conjugative transfer protein complexes. Mol Microbiol. 2001; 42:705-715. [PubMed: 11722736]

52. Jakubowski SJ, et al. Agrobacterium VirB10 domain requirements for type IV secretion and T pilus biogenesis. Mol Microbiol. 2009; 71:779-794. [PubMed: 19054325]

53. Fronzes R, et al. Structure of a type IV secretion system core complex. Science. 2009; 323:266268. This study reports the first structure of a large T4SS assembly that is formed by the VirB7, VirB9 and VirB10 homologues that are encoded by the pKM101 conjugation plasmid. [PubMed: 19131631]

54. Das A, Xie YH. Construction of transposon Tn3phoA: its application in defining the membrane topology of the Agrobacterium tumefaciens DNA transfer proteins. Mol Microbiol. 1998; 27:405414. [PubMed: 9484895]

55. Terradot L, et al. Structures of two core subunits of the bacterial type IV secretion system, VirB8 from Brucella suis and ComB10 from Helicobacter pylori. Proc Natl Acad Sci USA. 2005; 102:4596-4601. This report describes the first structures of the periplasmic domains of two key T4SS components, VirB8 and VirB10. [PubMed: 15764702] 
56. Jakubowski SJ, Cascales E, Krishnamoorthy V, Christie PJ. Agrobacterium tumefaciens VirB9, an outer-membrane-associated component of a type IV secretion system, regulates substrate selection and T-pilus biogenesis. J Bacteriol. 2005; 187:3486-3495. [PubMed: 15866936]

57. Bayliss R, et al. NMR structure of a complex between the VirB9/VirB7 interaction domains of the pKM101 type IV secretion system. Proc Natl Acad Sci USA. 2007; 104:1673-1678. This article describes the first structure of a binary complex between the soluble, periplasmic parts of VirB9 and VirB7. [PubMed: 17244707]

58. Cascales E, Christie PJ. Agrobacterium VirB10, an ATP energy sensor required for type IV secretion. Proc Natl Acad Sci USA. 2004; 101:17228-17233. [PubMed: 15569944]

59. Song L, et al. Structure of staphylococcal a-hemolysin, a heptameric transmembrane pore. Science. 1996; 274:1859-1866. [PubMed: 8943190]

60. Olson R, Nariya H, Yokota K, Kamio Y, Gouaux E. Crystal structure of staphylococcal LukF delineates conformational changes accompanying formation of a transmembrane channel. Nature Struct Biol. 1999; 6:134-140. [PubMed: 10048924]

61. Cascales E, Christie PJ. Definition of a bacterial type IV secretion pathway for a DNA substrate. Science. 2004; 304:1170-1173. This study describes the interaction of a T4S substrate with the secretion machinery components. [PubMed: 15155952]

62. Buhrdorf R, Forster C, Haas R, Fischer W. Topological analysis of a putative virB8 homologue essential for the cag type IV secretion system in Helicobacter pylori. Int J Med Microbiol. 2003; 293:213-217. [PubMed: 12868658]

63. Kumar RB, Xie YH, Das A. Subcellular localization of the Agrobacterium tumefaciens T-DNA transport pore proteins: VirB8 is essential for the assembly of the transport pore. Mol Microbiol. 2000; 36:608-617. [PubMed: 10844650]

64. Judd PK, Kumar RB, Das A. The type IV secretion apparatus protein VirB6 of Agrobacterium tumefaciens localizes to a cell pole. Mol Microbiol. 2005; 55:115-124. [PubMed: 15612921]

65. Baron C. VirB8: a conserved type IV secretion system assembly factor and drug target. Biochem Cell Biol. 2006; 84:890-899. [PubMed: 17215876]

66. Bailey S, Ward D, Middleton R, Grossmann JG, Zambryski PC. Agrobacterium tumefaciens VirB8 structure reveals potential protein-protein interaction sites. Proc Natl Acad Sci USA. 2006; 103:2582-2587. [PubMed: 16481621]

67. Karnholz A, et al. Functional and topological characterization of novel components of the comB DNA transformation competence system in Helicobacter pylori. J Bacteriol. 2006; 188:882-893. [PubMed: 16428391]

68. Jakubowski SJ, Krishnamoorthy V, Cascales E, Christie PJ. Agrobacterium tumefaciens VirB6 domains direct the ordered export of a DNA substrate through a type IV secretion system. J Mol Biol. 2004; 341:961-977. [PubMed: 15328612]

69. Kumar RB, Das A. Functional analysis of the Agrobacterium tumefaciens T-DNA transport pore protein VirB8. J Bacteriol. 2001; 183:3636-3641. [PubMed: 11371528]

70. Krall L, et al. Detergent extraction identifies different VirB protein subassemblies of the type IV secretion machinery in the membranes of Agrobacterium tumefaciens. Proc Natl Acad Sci USA. 2002; 99:11405-11410. [PubMed: 12177443]

71. Jakubowski SJ, Krishnamoorthy V, Christie PJ. Agrobacterium tumefaciens VirB6 protein participates in formation of VirB7 and VirB9 complexes required for type IV secretion. $\mathrm{J}$ Bacteriol. 2003; 185:2867-2878. [PubMed: 12700266]

72. Das A, Xie YH. The Agrobacterium T-DNA transport pore proteins VirB8, VirB9, and VirB10 interact with one another. J Bacteriol. 2000; 182:758-763. [PubMed: 10633111]

73. Rambow-Larsen AA, Weiss AA. The PtlE protein of Bordetella pertussis has peptidoglycanase activity required for Ptl-mediated pertussis toxin secretion. J Bacteriol. 2002; 184:2863-2869. [PubMed: 12003925]

74. Hoppner C, Carle A, Sivanesan D, Hoeppner S, Baron C. The putative lytic transglycosylase VirB1 from Brucella suis interacts with the type IV secretion system core components VirB8, VirB9 and VirB11. Microbiology. 2005; 151:3469-3482. [PubMed: 16272371]

75. Bayer M, et al. Gene 19 of plasmid R1 is required for both efficient conjugative DNA transfer and bacteriophage R17 infection. J Bacteriol. 1995; 177:4279-4288. [PubMed: 7543471] 
76. Koraimann G. Lytic transglycosylases in macromolecular transport systems of Gram-negative bacteria. Cell Mol Life Sci. 2003; 60:2371-2388. [PubMed: 14625683]

77. Lai EM, Chesnokova O, Banta LM, Kado CI. Genetic and environmental factors affecting T-pilin export and T-pilus biogenesis in relation to flagellation of Agrobacterium tumefaciens. J Bacteriol. 2000; 182:3705-3716. [PubMed: 10850985]

78. Fullner KJ, Lara JC, Nester EW. Pilus assembly by Agrobacterium T-DNA transfer genes. Science. 1996; 273:1107-1109. [PubMed: 8688097]

79. Berger BR, Christie PJ. Genetic complementation analysis of the Agrobacterium tumefaciens virB operon: virB2 through virB11 are essential virulence genes. J Bacteriol. 1994; 176:3646-3660. [PubMed: 8206843]

80. Bayer M, et al. Functional and mutational analysis of P19, a DNA transfer protein with muramidase activity. J Bacteriol. 2001; 183:3176-3183. [PubMed: 11325947]

81. Baron C, Llosa M, Zhou S, Zambryski PC. VirB1, a component of the T-complex transfer machinery of Agrobacterium tumefaciens, is processed to a C-terminal secreted product, VirB1. J Bacteriol. 1997; 179:1203-1210. [PubMed: 9023203]

82. Zupan J, Hackworth CA, Aguilar J, Ward D, Zambryski P. VirB1* promotes T-pilus formation in the vir-type IV secretion system of Agrobacterium tumefaciens. J Bacteriol. 2007; 189:6551-6563. [PubMed: 17631630]

83. Beijersbergen A, Smith SJ, Hooykaas PJ. Localization and topology of VirB proteins of Agrobacterium tumefaciens. Plasmid. 1994; 32:212-218. [PubMed: 7846145]

84. Grahn AM, Haase J, Bamford DH, Lanka E. Components of the RP4 conjugative transfer apparatus form an envelope structure bridging inner and outer membranes of donor cells: implications for related macromolecule transport systems. J Bacteriol. 2000; 182:1564-1574. [PubMed: 10692361]

85. Batchelor RA, Pearson BM, Friis LM, Guerry P, Wells JM. Nucleotide sequences and comparison of two large conjugative plasmids from different Campylobacter species. Microbiology. 2004; 150:3507-3517. [PubMed: 15470128]

86. Christie PJ. Agrobacterium tumefaciens T-complex transport apparatus: a paradigm for a new family of multifunctional transporters in eubacteria. J Bacteriol. 1997; 179:3085-3094. [PubMed: 9150199]

87. Haase J, Lurz R, Grahn AM, Bamford DH, Lanka E. Bacterial conjugation mediated by plasmid RP4: RSF1010 mobilization, donor-specific phage propagation, and pilus production require the same Tra2 core components of a proposed DNA transport complex. J Bacteriol. 1995; 177:4779_ 4791. [PubMed: 7642506]

88. Babic A, Lindner AB, Vulic M, Stewart EJ, Radman M. Direct visualization of horizontal gene transfer. Science. 2008; 319:1533-1536. [PubMed: 18339941]

89. Shu AC, et al. Evidence of DNA transfer through F-pilus channels during Escherichia coli conjugation. Langmuir. 2008; 24:6796-6802. [PubMed: 18522439]

90. Kwok T, et al. Helicobacter exploits integrin for type IV secretion and kinase activation. Nature. 2007; 449:862-866. [PubMed: 17943123]

91. Eisenbrandt R, Kalkum M, Lurz R, Lanka E. Maturation of IncP pilin precursors resembles the catalytic dyad-like mechanism of leader peptidases. J Bacteriol. 2000; 182:6751-6761. [PubMed: 11073921]

92. Sagulenko E, Sagulenko V, Chen J, Christie PJ. Role of Agrobacterium VirB11 ATPase in T-pilus assembly and substrate selection. J Bacteriol. 2001; 183:5813-5825. [PubMed: 11566978]

93. Haase J, Lanka E. A specific protease encoded by the conjugative DNA transfer systems of IncP and Ti plasmids is essential for pilus synthesis. J Bacteriol. 1997; 179:5728-5735. [PubMed: 9294428]

94. Majdalani N, Ippen-Ihler K. Membrane insertion of the F-pilin subunit is Sec independent but requires leader peptidase B and the proton motive force. J Bacteriol. 1996; 178:3742-3747. [PubMed: 8682775]

95. Majdalani N, Moore D, Maneewannakul S, Ippen-Ihler K. Role of the propilin leader peptide in the maturation of F pilin. J Bacteriol. 1996; 178:3748-3754. [PubMed: 8682776] 
96. Moore D, et al. The Escherichia coli $\mathrm{K}-12 \mathrm{~F}$ plasmid gene $\operatorname{traX}$ is required for acetylation of $\mathrm{F}$ pilin. J Bacteriol. 1993; 175:1375-1383. [PubMed: 8444800]

97. Eisenbrandt R, et al. Conjugative pili of IncP plasmids, and the Ti plasmid T pilus are composed of cyclic subunits. J Biol Chem. 1999; 274:22548-22555. A remarkable work describing the complex maturation process that T4SS pilins undergo during pilus biogenesis. [PubMed: 10428832]

98. Kalkum M, Eisenbrandt R, Lurz R, Lanka E. Tying rings for sex. Trends Microbiol. 2002; 10:382387. [PubMed: 12160637]

99. Lai EM, Kado CI. Processed VirB2 is the major subunit of the promiscuous pilus of Agrobacterium tumefaciens. J Bacteriol. 1998; 180:2711-2717. [PubMed: 9573157]

100. Schmidt-Eisenlohr H, et al. Vir proteins stabilize VirB5 and mediate its association with the T pilus of Agrobacterium tumefaciens. J Bacteriol. 1999; 181:7485-7492. [PubMed: 10601205]

101. Schmidt-Eisenlohr H, Domke N, Baron C. TraC of IncN plasmid pKM101 associates with membranes and extracellular high-molecular-weight structures in Escherichia coli. J Bacteriol. 1999; 181:5563-5571. [PubMed: 10482495]

102. Yeo HJ, Yuan Q, Beck MR, Baron C, Waksman G. Structural and functional characterization of the VirB5 protein from the type IV secretion system encoded by the conjugative plasmid pKM101. Proc Natl Acad Sci USA. 2003; 100:15947-15952. The crystal structure of a VirB5 protein suggests that it functions as an adhesin. [PubMed: 14673074]

103. Aly KA, Baron C. The VirB5 protein localizes to the T-pilus tips in Agrobacterium tumefaciens. Microbiology. 2007; 153:3766-3775. [PubMed: 17975085]

104. Backert S, Fronzes R, Waksman G. VirB2 and VirB5 proteins: specialized adhesins in bacterial type-IV secretion systems? Trends Microbiol. 2008; 16:409-413. [PubMed: 18706815]

105. Bradley DE. Morphological and serological relationships of conjugative pili. Plasmid. 1980; 4:155-169. [PubMed: 6152840]

106. Andrzejewska J, et al. Characterization of the pilin ortholog of the Helicobacter pylori type IV cag pathogenicity apparatus, a surface-associated protein expressed during infection. J Bacteriol. 2006; 188:5865-5877. [PubMed: 16885455]

107. Rohde M, Puls J, Buhrdorf R, Fischer W, Haas R. A novel sheathed surface organelle of the Helicobacter pylori cag type IV secretion system. Mol Microbiol. 2003; 49:219-234. [PubMed: 12823823]

108. Tanaka J, Suzuki T, Mimuro H, Sasakawa C. Structural definition on the surface of Helicobacter pylori type IV secretion apparatus. Cell Microbiol. 2003; 5:395-404. [PubMed: 12780777]

109. Wang YA, Yu X, Silverman PM, Harris RL, Egelman EH. The structure of F-pili. J Mol Biol. 2009; 385:22-29. [PubMed: 18992755]

110. Fernandez D, et al. The Agrobacterium tumefaciens virB7 gene product, a proposed component of the T-complex transport apparatus, is a membrane-associated lipoprotein exposed at the periplasmic surface. J Bacteriol. 1996; 178:3156-3167. [PubMed: 8655494]

111. Judd PK, Kumar RB, Das A. Spatial location and requirements for the assembly of the Agrobacterium tumefaciens type IV secretion apparatus. Proc Natl Acad Sci USA. 2005; 102:11498-11503. [PubMed: 16076948]

112. Atmakuri K, Ding Z, Christie PJ. VirE2, a type IV secretion substrate, interacts with the VirD4 transfer protein at cell poles of Agrobacterium tumefaciens. Mol Microbiol. 2003; 49:1699-1713. [PubMed: 12950931]

113. Clarke M, Maddera L, Harris RL, Silverman PM. F-pili dynamics by live-cell imaging. Proc Natl Acad Sci USA. 2008; 105:17978-17981. [PubMed: 19004777]

114. Filloux A. The underlying mechanisms of type II protein secretion. Biochim Biophys Acta. 2004; 1694:163-179. [PubMed: 15546665]

115. Koronakis V, Hughes C, Koronakis E. Energetically distinct early and late stages of HlyB/HlyDdependent secretion across both Escherichia coli membranes. EMBO J. 1991; 10:3263-3272. [PubMed: 1915293]

116. Omori K, Idei A. Gram-negative bacterial ATP-binding cassette protein exporter family and diverse secretory proteins. J Biosci Bioeng. 2003; 95:1-12. [PubMed: 16233359]

117. Gold VA, Duong F, Collinson I. Structure and function of the bacterial Sec translocon. Mol Membr Biol. 2007; 24:387-394. [PubMed: 17710643] 
118. Voulhoux R, et al. Involvement of the twin-arginine translocation system in protein secretion via the type II pathway. EMBO J. 2001; 20:6735-6741. [PubMed: 11726509]

119. Peabody CR, et al. Type II protein secretion and its relationship to bacterial type IV pili and archaeal flagella. Microbiology. 2003; 149:3051-3072. [PubMed: 14600218]

120. Craig L, Li J. Type IV pili: paradoxes in form and function. Curr Opin Struct Biol. 2008; 18:267277. [PubMed: 18249533]

121. Cornelis GR, Van Gijsegem F. Assembly and function of type III secretory systems. Annu Rev Microbiol. 2000; 54:735-774. [PubMed: 11018143]

122. Galan JE, Wolf-Watz H. Protein delivery into eukaryotic cells by type III secretion machines. Nature. 2006; 444:567-573. [PubMed: 17136086]

123. Henderson IR, Navarro-Garcia F, Desvaux M, Fernandez RC, Ala'Aldeen D. Type V protein secretion pathway: the autotransporter story. Microbiol Mol Biol Rev. 2004; 68:692-744. [PubMed: 15590781]

124. Henderson IR, Nataro JP. Virulence functions of autotransporter proteins. Infect Immun. 2001; 69:1231-1243. [PubMed: 11179284]

125. Mazar J, Cotter PA. New insight into the molecular mechanisms of two-partner secretion. Trends Microbiol. 2007; 15:508-515. [PubMed: 17988872]

126. Cascales E. The type VI secretion toolkit. EMBO Rep. 2008; 9:735-741. [PubMed: 18617888]

127. Pukatzki S, McAuley SB, Miyata ST. The type VI secretion system: translocation of effectors and effector-domains. Curr Opin Microbiol. 2009; 12:11-17. [PubMed: 19162533]

128. Cascales E, Christie PJ. The versatile bacterial type IV secretion systems. Nature Rev Microbiol. 2003; 1:137-149. [PubMed: 15035043]

129. Dehio C. Infection-associated type IV secretion systems of Bartonella and their diverse roles in host cell interaction. Cell Microbiol. 2008; 10:1591-1598. [PubMed: 18489724]

130. Sagulenko V, Sagulenko E, Jakubowski S, Spudich E, Christie PJ. VirB7 lipoprotein is exocellular and associates with the Agrobacterium tumefaciens T pilus. J Bacteriol. 2001; 183:3642-3651. [PubMed: 11371529]

131. Jones AL, Shirasu K, Kado CI. The product of the virB4 gene of Agrobacterium tumefaciens promotes accumulation of VirB3 protein. J Bacteriol. 1994; 176:5255-5261. [PubMed: 8071199]

132. Strauch E, et al. A cryptic plasmid of Yersinia enterocolitica encodes a conjugative transfer system related to the regions of CloDF13 Mob and IncX Pil. Microbiology. 2003; 149:28292845. [PubMed: 14523116]

133. Shamaei-Tousi A, Cahill R, Frankel G. Interaction between protein subunits of the type IV secretion system of Bartonella henselae. J Bacteriol. 2004; 186:4796-4801. [PubMed: 15231811]

134. Anderson LB, Hertzel AV, Das A. Agrobacterium tumefaciens VirB7 and VirB9 form a disulfidelinked protein complex. Proc Natl Acad Sci USA. 1996; 93:8889-8894. [PubMed: 8799123]

135. Baron C, Thorstenson YR, Zambryski PC. The lipoprotein VirB7 interacts with VirB9 in the membranes of Agrobacterium tumefaciens. J Bacteriol. 1997; 179:1211-1218. [PubMed: 9023204]

136. Das A, Anderson LB, Xie YH. Delineation of the interaction domains of Agrobacterium tumefaciens VirB7 and VirB9 by use of the yeast two-hybrid assay. J Bacteriol. 1997; 179:34043409. [PubMed: 9171381]

137. Farizo KM, Cafarella TG, Burns DL. Evidence for a ninth gene, ptlI, in the locus encoding the pertussis toxin secretion system of Bordetella pertussis and formation of a PtlI-PtlF complex. J Biol Chem. 1996; 271:31643-31649. [PubMed: 8940184]

138. Harris RL, Hombs V, Silverman PM. Evidence that F-plasmid proteins TraV, TraK and TraB assemble into an envelope-spanning structure in Escherichia coli. Mol Microbiol. 2001; 42:757766. [PubMed: 11722740]

139. Spudich GM, Fernandez D, Zhou XR, Christie PJ. Intermolecular disulfide bonds stabilize VirB7 homodimers and VirB7/VirB9 heterodimers during biogenesis of the Agrobacterium tumefaciens T-complex transport apparatus. Proc Natl Acad Sci USA. 1996; 93:7512-7517. [PubMed: 8755505] 
140. Beaupre CE, Bohne J, Dale EM, Binns AN. Interactions between VirB9 and VirB10 membrane proteins involved in movement of DNA from Agrobacterium tumefaciens into plant cells. $\mathrm{J}$ Bacteriol. 1997; 179:78-89. [PubMed: 8981983] 
a Conjugation

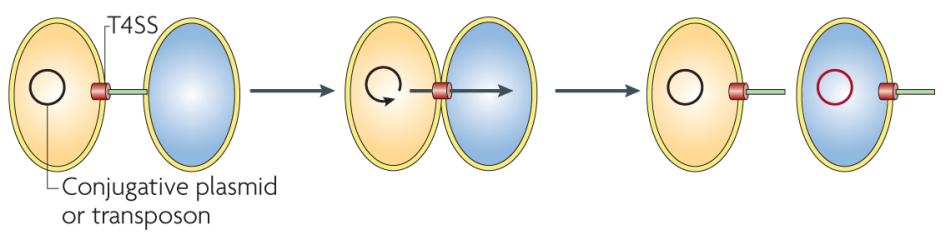

b DNA uptake (transformation) and release
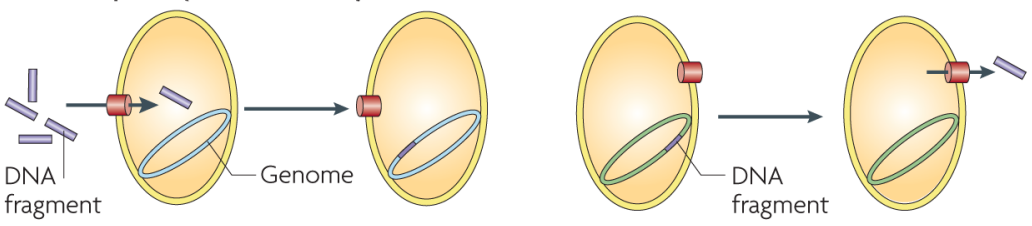

C Effector translocation

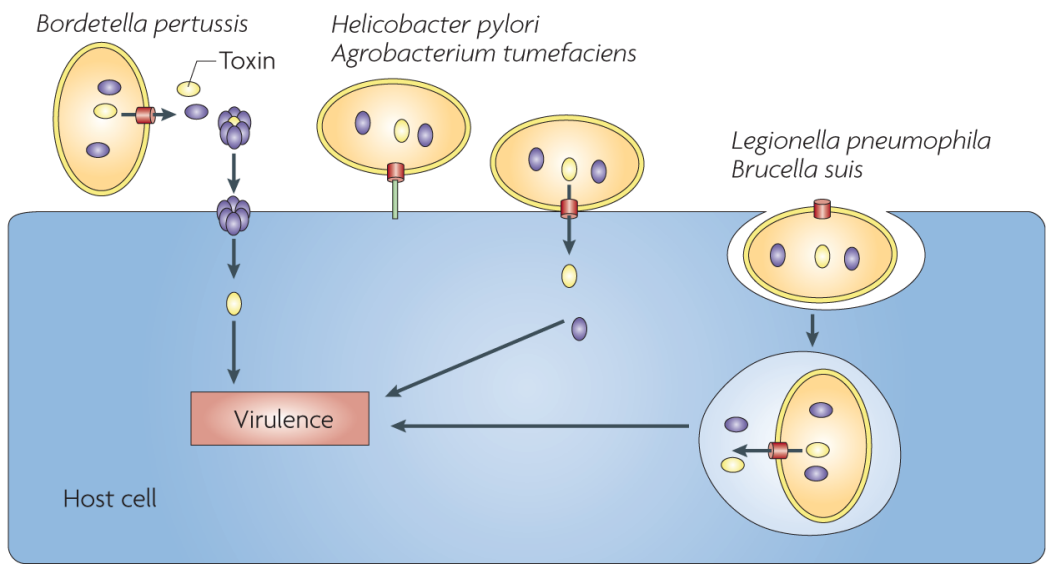

Figure 1. Schematic of the role of type IV secretion in bacteria

The three groups of type IV secretion apparatus are shown. a | Conjugative type IV secretion systems (T4SSs) deliver plasmids or transposons from donor cell to recipient cell in Gramnegative and Gram-positive bacteria. b | DNA uptake (transformation) and release T4SSs mediate the exchange of DNA with the extracellular milieu. $\mathbf{c}$ |Effector translocation T4SSs deliver DNA or protein substrates to eukaryotic cells and are directly involved in the virulence of many pathogenic Gram-negative bacteria (for further details, see REFS $10,11,128,129)$. 
a

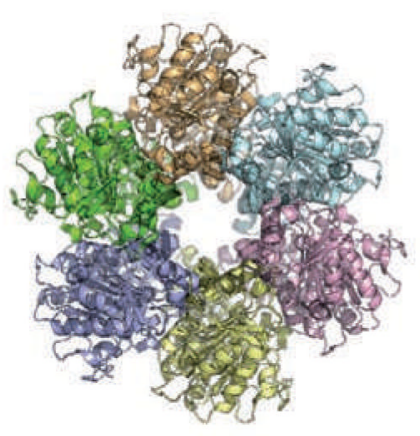

VirD4 hexamer

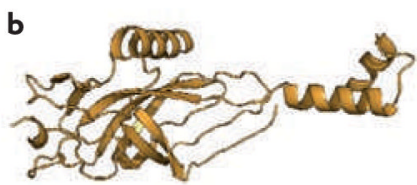

VirB10
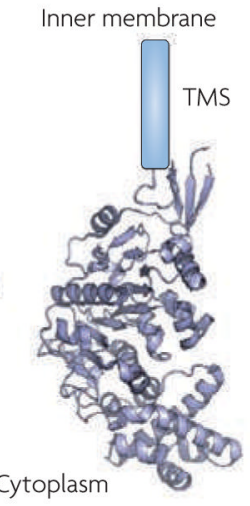

VirD4 monomer

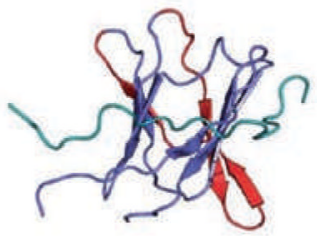

VirB7-VirB9

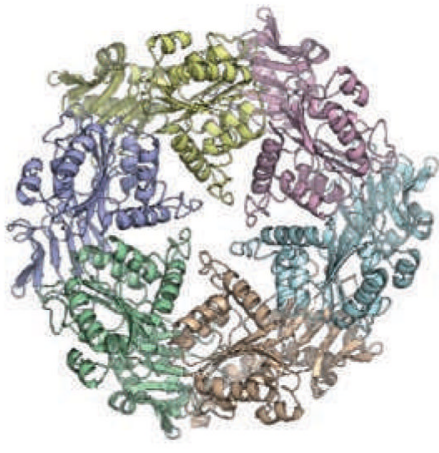

VirBll hexamer

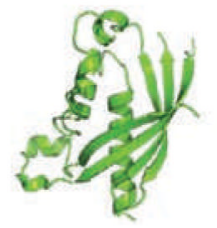

VirB8

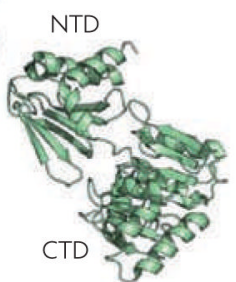

VirB11 monomer

Figure 2. Atomic structures of type IV secretion system components or domains

All structures are shown in a ribbon representation. a |The structure of the VirD4 homologue TrwB hexamer and monomer is shown on the left; TrwB is encoded by the Escherichia coli conjugative plasmid R388 (REF. 18). The crystal structures of the Helicobacter pylori VirB11 homologue HP5025 hexamer and monomer are shown on the right (REFS 33,34). b | From left to right, the structures shown are: the crystal structure of the periplasmic carboxy-terminal domain of the H. pylori VirB10 homologue ComB10 (REF. 55); the nuclear magnetic resonance spectroscopy structure of the C-terminal domain of the VirB9 homologue TraO (in blue, with the $\beta$-appendage in red), which is encoded by the $E$. coli pKM101 conjugative plasmid, in complex with the VirB7 homologue $\mathrm{TraN}^{57}$ (in cyan); the crystal structure of the periplasmic C-terminal domain of VirB8 from Brucella suis and Agrobacterium tumefaciens ${ }^{55,66}$; and the crystal structure of the VirB5 homologue TraC, which is encoded by the E. coli conjugative plasmid pKM101 (REF. 102). CTD, carboxyterminal domain; NTD, amino-terminal domain; TMS, transmembrane segment. 


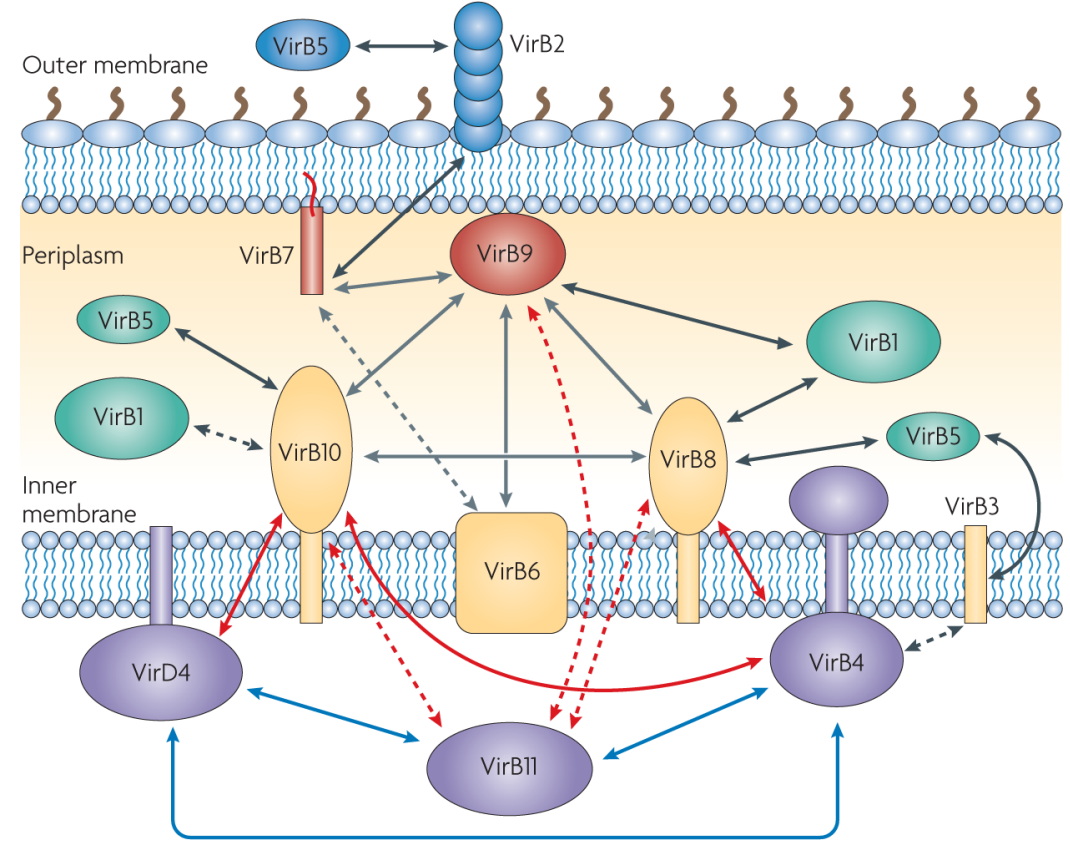

Figure 3. Schematic of the localization of the Agrobacterium tumefaciens VirB/D type IV secretion components and their interactions

The VirD4 and VirB1-VirB11 type IV secretion system (T4SS) components are shown according to their proposed localization (cytoplasmic ATPases are shown in purple, inner membrane proteins in yellow, periplasmic proteins in green, outer membrane proteins in red and extracellular proteins in blue). Interactions between ATPases are shown with blue arrows. Interactions between ATPases and any non-ATPase T4SS component are shown with red arrows. Interactions between T4SS core components are shown with grey arrows. Black arrows indicate other interactions. Possible interactions are indicated by dotted arrows. The publications corresponding to each interaction are: VirB1-VirB8 (REFS 45,73,74); VirB1-VirB9 (REFS 45,74); VirB1-VirB10 (REF. 45); VirB2-VirB5 (REFS 44,100,101,103); VirB2-VirB7 (REFS 70,130); VirB3-VirB4 (REFS 44,85,131,132); VirB3-VirB5 (REF. 133); VirB4-VirB8 (REFS 44,45,48); VirB4-VirB10 (REFS 45-48); VirB4-VirB11 (REFS 45,49); VirB4-VirD4 (REFS 48,49); VirB5-VirB8 (REF. 44); VirB5-VirB10 (REF. 44); VirB6-VirB7 (REFS 70,71); VirB6-VirB9 (REF. 71); VirB7VirB9 (REFS 45,53,57,72,134-139); VirB8-VirB9 (REFS 48,69,70,72); VirB8-VirB10 (REFS 69,70,72); VirB8-VirB11 (REF. 45); VirB9-VirB10 (REFS 48,53,58,69,70,72,140); VirB9-VirB11 (REFS 45,48); VirB10-VirB11 (REF. 45); VirB11-VirD4 (REF. 49). 

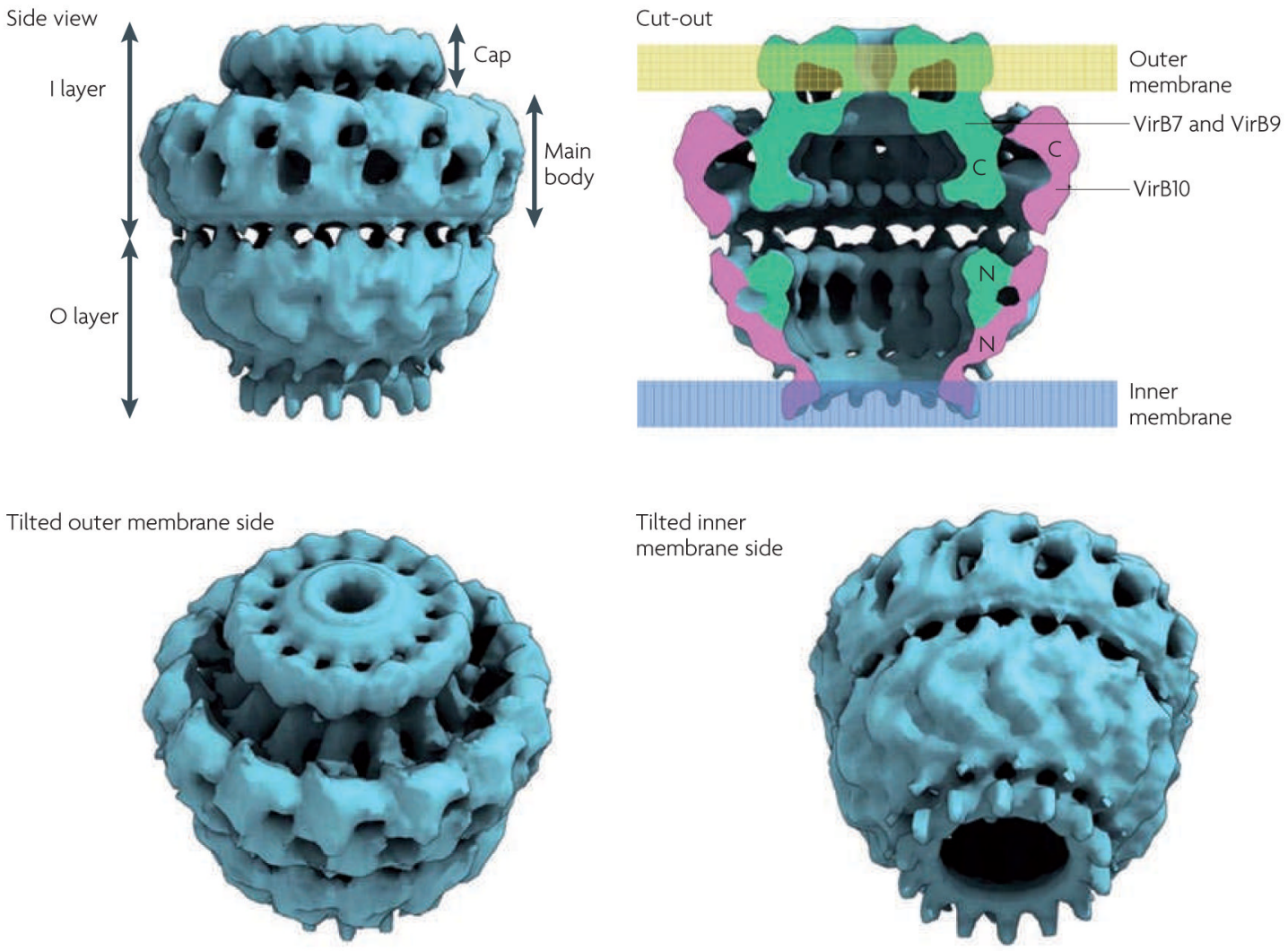

Figure 4. Structure of a type IV secretion core complex

The core complex ${ }^{53}$ is composed of TraN (a VirB7 homologue), TraO (a VirB9 homologue) and TraF (a VirB10 homologue), which are encoded by the Escherichia coli conjugative plasmid pKM101. This structure was obtained using cryoelectron microscopy and is viewed from the side (upper left panel), tilted towards the outer membrane side (lower left panel) and tilted towards the inner membrane side (lower right panel). The cut-out view (upper right panel) details the proposed transmembrane regions and the localization of the VirB7, VirB9 and VirB10 homologues within the structure. C, carboxy-terminal domain; N, aminoterminal domain. 


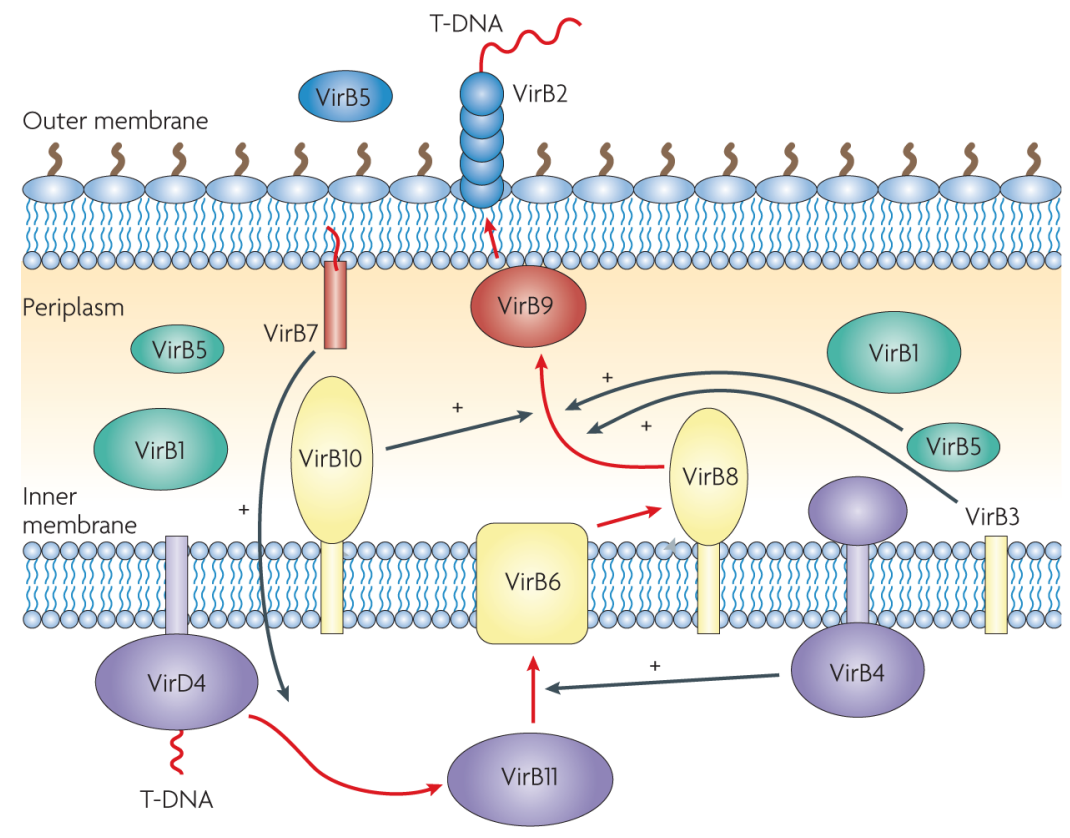

Figure 5. Translocation of T-DNA

The figure shows the T-DNA translocation pathway within the type IV secretion apparatus of Agrobacterium tumefaciens, as determined by the transfer DNA immunoprecipitation asssay ${ }^{61}$. The substrate pathway is shown in red arrows. The T-DNA interacts directly with VirD4, VirB11, VirB6, VirB8 and finally with VirB9-VirB2. The other components influence the transfer of the substrate at different stages, as shown by black arrows. 
a Translocation pore assembly
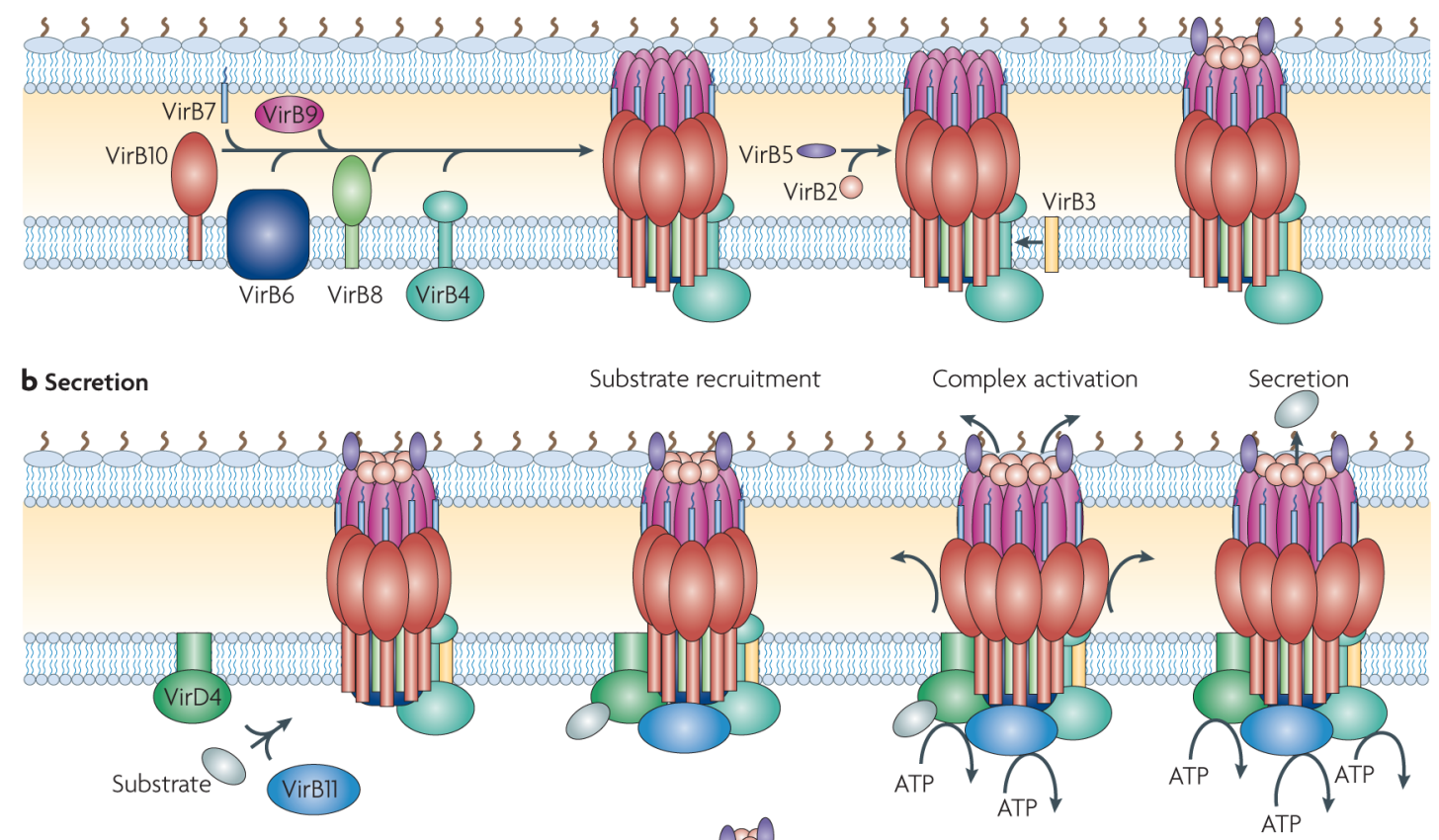

c Pilus biogenesis

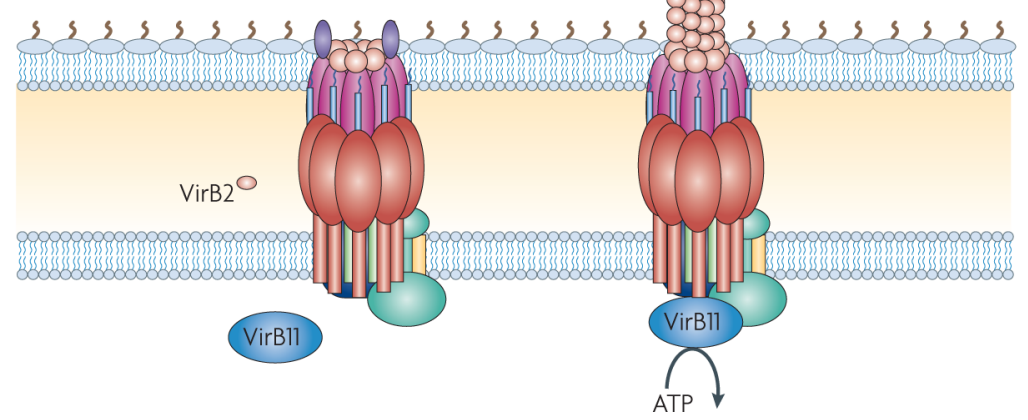

Figure 6. Schematic of the assembly and function of a type IV secretion system a | The translocation pore consists of the core complex proteins VirB7, VirB9 and VirB10, the inner-membrane pore proteins VirB6 and VirB8, VirB4, the pilus-associated proteins VirB2, VirB3 and VirB5, and possibly VirB1. b|Depending on unidentified stimuli, the complex could further assemble to secrete a substrate, by the addition of VirD4 and VirB11. Arrows around VirB10 indicate potential conformational changes linked to ATP-binding and hydrolysis by cytoplasmic-inner membrane ATPases. c | Alternatively, the complex could assemble a pilus with the addition of VirB11. 